\title{
DYNAMIC MANAGEMENT OF ROAD CONSTRUCTION OPERATIONS ON SITE
}

\author{
*Heikkilä, R. \\ University of Oulu \\ Erkki Koiso-Kanttilankatu 1 \\ Oulu, Finland \\ (*Corresponding author: rauno.heikkila@oulu.fi) \\ Tiitinen, $\mathrm{P}$. \\ University of Oulu \\ Erkki Koiso-Kanttilankatu 1 \\ Oulu, Finland
}

\begin{abstract}
Today road construction sites utilize more and more information modeling in design phases as well as model based 3-D machine control systems in site operations. For main contractor, the management and control of all the site operations is a demanding task including also many challenges created by continuously developing new technology. In the paper, the main requirements for successful dynamic site management are introduced. The dynamic management means real-time possibilities for information acquiring, transfer and further utilization of the information in the management. An integration model to expand the current way of management and the utilization of present 3-D machine control systems is introduced. Different practical test results using two new different dynamic management systems are presented and evaluated. The first experiments and the results have been provided using the prototype system developed in a research project called DigiINFRA by the University of Oulu and Technical Research Center of Finland. Also, there have been tested a new commercial management system developed recently in Finland. In the conclusion, an expectation for the next generation for more dynamic road construction management methods is concluded.
\end{abstract}

\section{KEYWORDS}

\section{Road Construction, Site Operations, Dynamic Management.}

\section{INTRODUCTION}

The aim of automation in road construction and maintenance is to increase production efficiency, improve product quality, and enhance workers' safety (see for example, West, et al. 1995, Woo, D.-C. 1995). The ongoing increase in use of automation in road construction and maintenance is a clear signal about the economic benefits achieved by automation, i.e. three-dimensional process and different automated tools through the main phases of the measurement, design, construction, and maintenance processes (Heikkilä et al. 2006). There have been only a few scientific papers focused on the economic benefits and savings achieved by the aid of automation for road processes-no detailed and comprehensive research has been reported. In some countries, such as in Northern Scandinavia, this has not prevented the fast spread and use of automation technologies, but in general there are still areas and countries where automation is underutilized. To facilitate greater use and the associated benefits, there is a strong need for a new study to measure and show the achievable economic benefits and savings.

There is also a group of new technological possibilities for additional savings and benefits. For example, present 3-D machine control systems have been developed for single working machines and for their own surrounding operational needs. In practice, most machines are working in machine groups, in which every machine and operator is responsible to perform their work tasks as a part of wider and often more complicated work process. Therefore, one of the most interesting new possibilities is to develop 
cooperation between multiple simultaneously working machines, as well as with the common work process design and project management systems. There are several possibilities to add intelligence into the cooperation of the working machines as well as to the information chains between machine control systems and 3D design software.

Several large related research projects have been carried out in Europe. The main aim of the CIRC (Computer Integrated Road Construction Project, 1997-1999, funded by the European Union) project was to create a digital link between the design office and the job site (Peyret et al. 2000). The main benefits achieved by the developed CIRC products were:

- Saving of tedious labor and associated costs. An 80,000 EURO investment could be paid off thanks to this savings on a single $30-\mathrm{km}$-long highway work site.

- Saving of equipment use. Two 62,000 EURO equipment investments could be paid of by this saving on two 30-km-long highway work sites.

- Saving of material, approximately 3,500 EURO/km on a $2 \times 2$ way highway pavement site.

- Improvement of quality, and reduction of supplementary costs for repairing low-quality work.

OSYRIS (Open System for Road Information Support, 2000-2003, funded by the European Union), the second largest European research project, included focus on the cost of inadequate interoperability (Ligier et al. 2001). In the project, the development of information management through the construction process and phases was seen as a key for new challenges and savings. In the short term, they identified direct savings for contractors, based on smart control and documentation, providing a digital, continuous quality management system, as well as for owners, based on time savings and reduced risk of error. In the long term, benefits were seen based on capture of relevant information for the next phases of the road life cycle, i.e. maintenance or rehabilitation work.

Intelligent Road Construction Site (Älykäs tietyömaa, 2000-2004, funded by Tekes and Finnish owners and companies) in Finland was the third largest investigation into the automation of road construction in Europe. The most accurate labor productivity studies were related to road grading (Heikkila \& Jaakkola 2002). According to detailed work studies on a motorway construction project, the work productivity was doubled when using the automated 3-D blade control system developed under the project. Simultaneously, the accuracy of graded road surface was very high (approx. $\pm 1 \ldots 2 \mathrm{~cm}$ ).

A work process study was made by Caterpillar in Spain 2006 at their Malaga Demonstration and Learning Center. According to the report (Caterpillar 2006), two identical 80 meter long roads were built (in the same area, close together, and using the same materials, machine models, machines and operators, and weather conditions), one using conventional methods, the other using 3D machine control systems. The roads included cuts, fills, curves, elevation changes and super elevations. The study measured time for all different operations, number of passes, buckets or truckloads, fuel consumption, and accuracies to compare the two methods. The main results were (Caterpillar 2006):

- Overall time for building the road was $3 \frac{1}{2}$ days vs. $1 \frac{1}{2}$ when using automation (AccuGrade System in this case).

- Increased in overall job site productivity of $101 \%$.

- Higher and more consistent accuracy (subgrade $86 \%$ within tolerance of $\pm 2 \mathrm{~cm}$, base course $98 \%$ within tolerance of $\pm 2 \mathrm{~cm}$ ).

- $43 \%$ fuel savings on average (excavator, road grader, bulldozer, truck).

Today road construction sites utilize more and more information modeling in design phases as well as model based 3-D machine control systems in site operations. For main contractor, the management and control of all the site operations is a demanding task including also many challenges created by continuously developing new technology. The goal of this study was to develop a model and a system for dynamic management of road construction site. The dynamic management was determined in this study to mean flexible, fast and efficient reaction to the control of different working tasks on site. In addition, dynamic management was determined to be such as system that is information modeling (BIM) based, 
internet browser-based, independent of different terminals, and utilizes wireless and mobile information transfer.

\section{METHODS}

Road construction sites today use modern 3D-machine control systems widely. Purpose of the research is to study how these control systems can communicate with site management systems. Idea is to help real time management of a road construction site. When working, real time system will speed up the work, produces better quality and lowers the costs.

Present management systems and models were studied and how to develop a dynamic management system and -model through data - and automation integration. An technology mapping survey was done to get the newest information about available current systems and software related to dynamic management. Semantic database as a base for management system was also studied as a new way to search information for management purposes. A prototype for dynamic site control center was specified and programmed as a part of the DigiINFRA research project (University of Oulu, VTT). The prototype was tested with limited functionality on a campus TestSite. Test included the dynamic control of one excavator and four truck systems. Several present road construction sites were visited, where the site management personnel were interviewed. These sites used most advanced site management systems. A special workshop, to the selected site managers of the contractor in question as well as the researchers obtaining a special knowledge from the area was done. In the workshop, different main functions of the dynamic road construction management, the priorities of these functions as well as update needs were studied and documented.

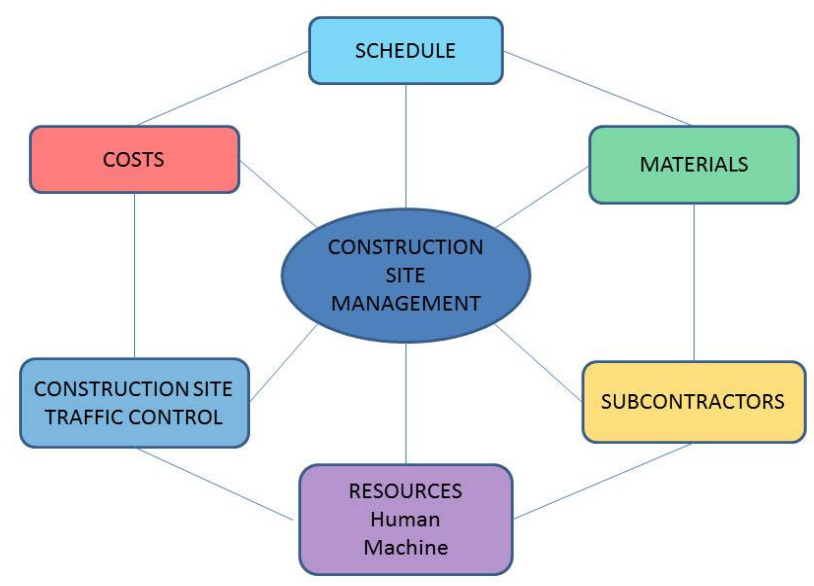

Figure 1. The identified main functions of dynamic management of road construction site. 


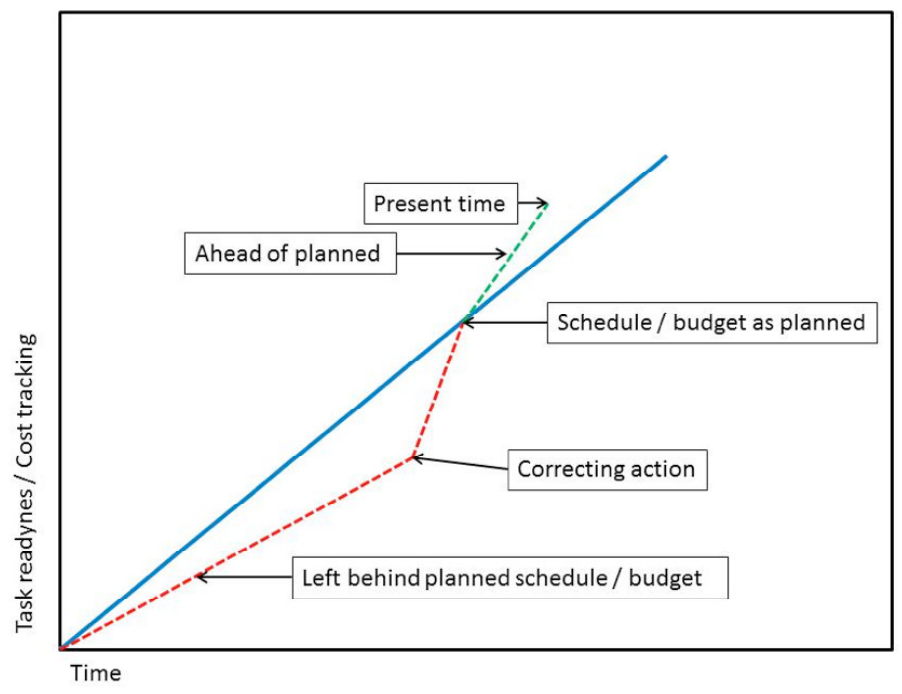

Figure 2. The principle of dynamic management for schedule control.

\section{RESULTS}

Empiric results show the use of many different systems, which do not yet communicate with management systems, or themselves. Components for several areas exist, but integration of functions has not happened yet. The benefits of 3-D machine control systems are clear and known and these systems are widely in use by many operators. Direction of development is towards greater integration. Use of integrated systems saves time and money and creates better quality.

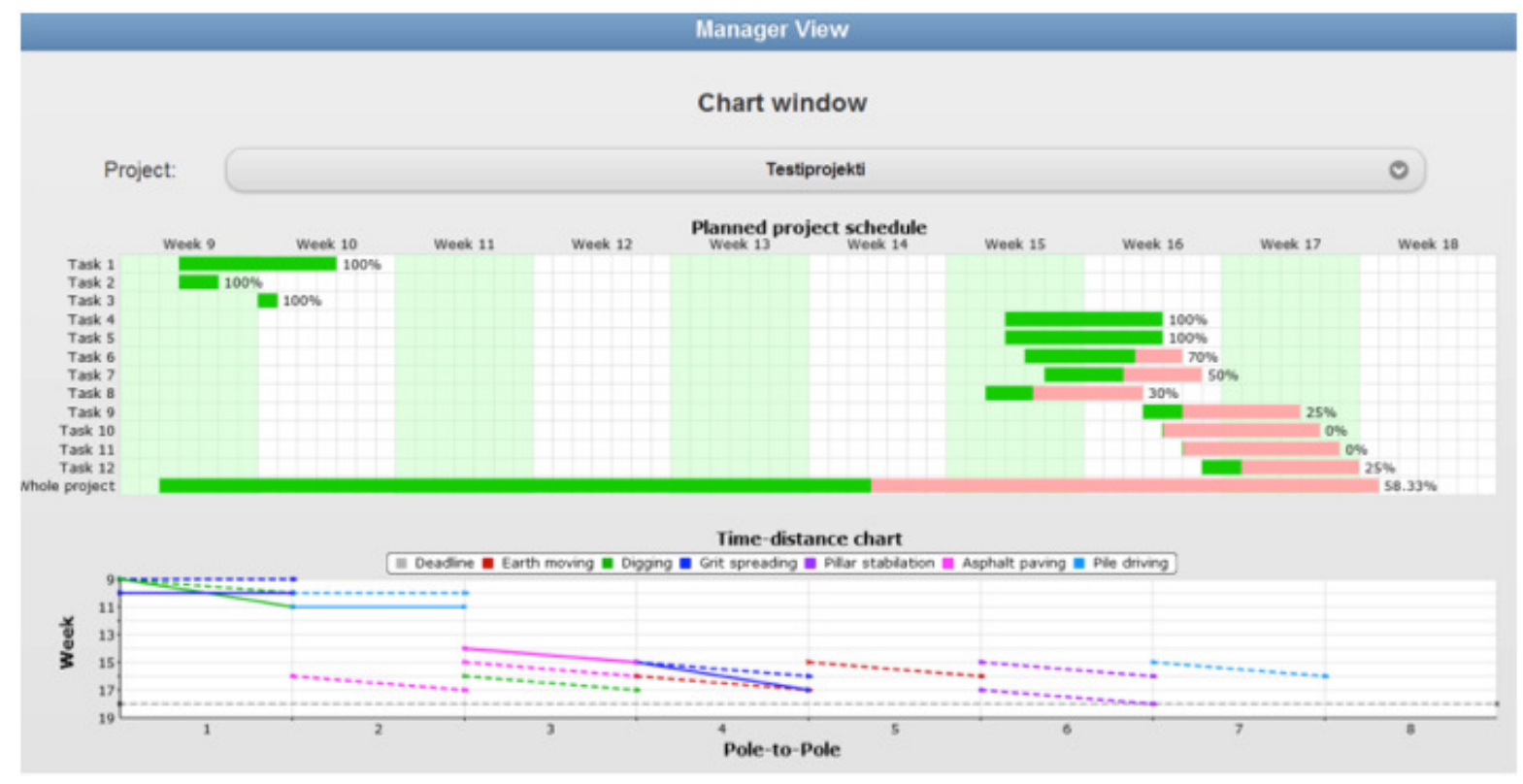

Figure 4. An user-interface of the Dynamic Site Control System DSCC) developed in the DigiINFRA research project (VTT, Finland). 
Table 1. The results of the priority study of main dynamic management functions.

\begin{tabular}{|c|c|c|c|c|c|c|c|c|}
\hline User Interface feature/functionality & Priority & & & & & & & Update or usage interval \\
\hline 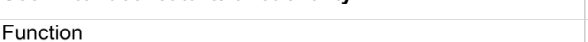 & {$[1 \ldots 5]$} & & & & & & & \\
\hline $\begin{array}{l}\text { Function } \\
\text { Display location of machines and trucks on map base }\end{array}$ & U1 & 52 & 4 & C4 & C 3 & 06 & $5 \quad \begin{array}{l}\text { Average } \\
4.5\end{array}$ & $\min , \min , d, d,-h$ \\
\hline Location information, where is a machine or a truck & 5 & 4 & 5 & 5 & 3 & 5 & $5 \quad 4.5$ & $\min , h, h, h,-, \min$ \\
\hline $\begin{array}{l}\text { Progress of a task on critical path, readyness of task vs. time } \\
\text { and vs. scheduled }\end{array}$ & b & b & b & 1 & b & b & 4.3 & $h, h, h, v k,-, h$ \\
\hline Displaying 3D-machine control model surfaces on map base & 5 & 5 & 4 & 5 & 1 & 5 & 4.2 & $\min , \min , d, d,-d$ \\
\hline $\begin{array}{l}\text { Display cross section picture of the structure on any chosen } \\
\text { point }\end{array}$ & 5 & 5 & 3 & 5 & 2 & 5 & 4.2 & $h, \min , d, h, d$, \\
\hline Easy access to all documents in project through internet & 5 & 4 & 3 & 5 & 4 & 4 & 4.2 & $d, d, d, v k, k k, d$ \\
\hline $\begin{array}{l}\text { Automated work reporting through 3D-machine control } \\
\text { system }\end{array}$ & 5 & 4 & 4 & 2 & 5 & 5 & 4.2 & $h, d, d, d, d, d$ \\
\hline Activity information, is a machine or a truck working & 5 & 4 & 4 & 3 & 4 & 4 & 4.0 & $\min , h, h, h,-, d$ \\
\hline Finance situation, costs vs. time vs. budgeted & 5 & 3 & 5 & 1 & 5 & 5 & 4.0 & $h, v k, d, k k,-, d$ \\
\hline Intelligent search option, materials, documents etc. & 5 & 4 & 4 & 3 & 4 & 3 & 3.8 & $\min , h, d,-,-, d$ \\
\hline Changes to single task in project & 5 & 3 & 4 & 3 & 3 & 4 & 3.7 & $h, d, d, v k,-, d$ \\
\hline Displayıng used 3D-machine control tile of any machıne & b & 4 & 4 & b & 1 & 2 & 3.5 & $\mathrm{~m} ı \mathrm{n}, \mathrm{m} ı \mathrm{n}, \mathrm{d}, \mathrm{h},-, \mathrm{d}$ \\
\hline Display the activity status of machines & 4 & 4 & 3 & 3 & 3 & 3 & 3.3 & $h, \min , h, d,-, v k, v k$ \\
\hline Storage view, materials, supplies, accessories & 5 & 4 & 3 & 1 & 3 & 4 & 3.3 & $h, d, d, k k, v k, d$ \\
\hline On site traffic control plan, traffic signs on map base & 4 & 4 & 3 & 3 & 3 & 3 & 3.3 & $\min , d, h, v k, k k, d$ \\
\hline Notes, pictures and video with location information & 5 & 4 & 3 & 3 & 3 & 2 & 3.3 & $h,-, d, d,-, v k$ \\
\hline Easy accsess to whole project task listings & 5 & 2 & 3 & 3 & 3 & 3 & 3.2 & $h, v k, v k, v k,-, d$ \\
\hline Weather report, rain forecast & 5 & 2 & 2 & 4 & 3 & 3 & 3.2 & $h, h, d, d,-, d$ \\
\hline Display activity history of a machine on calendar format & 3 & 4 & 2 & 1 & 2 & 3 & 2.5 & $\mathrm{~d}, \mathrm{~min}, \mathrm{~d}, \mathrm{kk},-, \mathrm{kk}$ \\
\hline Phone number and id of the machine driver & 4 & 3 & 1 & 1 & 1 & 2 & 2.0 & $h, \min , v k, d, k k,-$ \\
\hline
\end{tabular}

The workshop for the evaluation of different functions for dynamic management set priorities for each identified function (Table 1). As the most important functions, for example the display of the location of machines and trucks on map, location information where is machine, or a truck, progress of a work task on critical path, status of a task compared to the scheduled, the display of 3-D machine control mode, the display of cross section, or easy access to all the documents of the project trough internet.

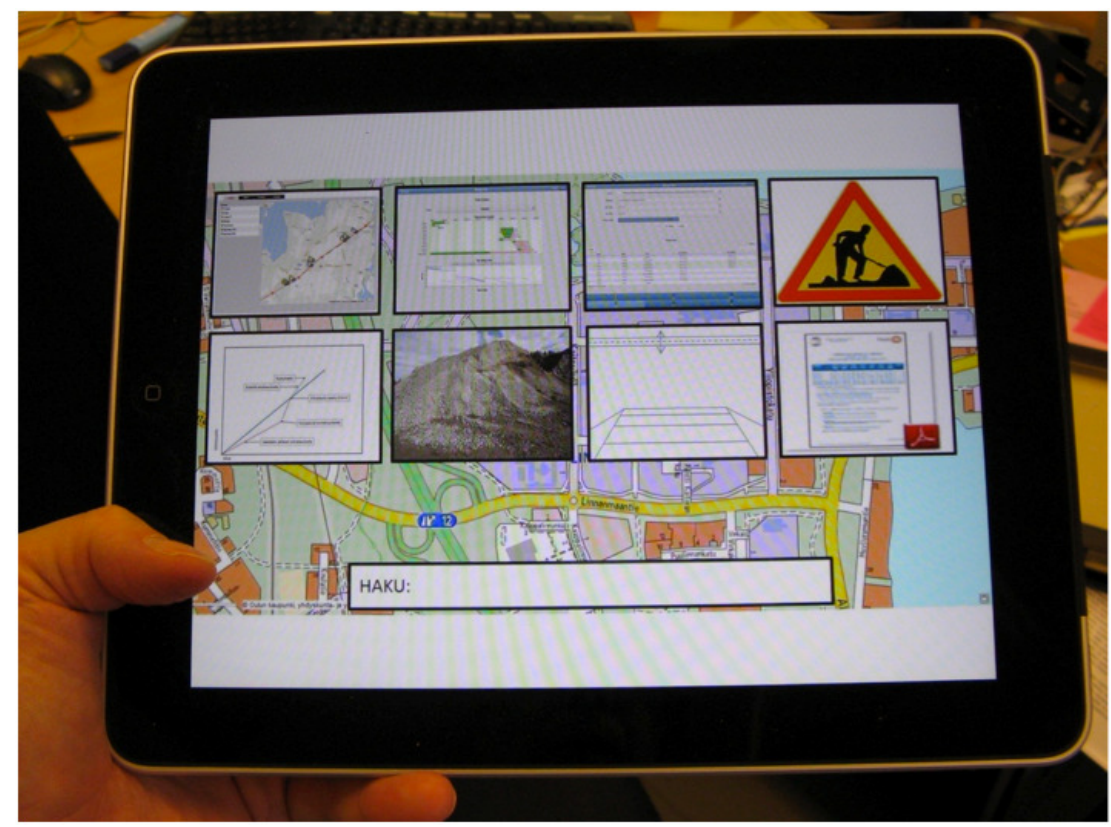

Figure 5. The integration of the systems - a draft for the user-interface of future dynamic management system. 

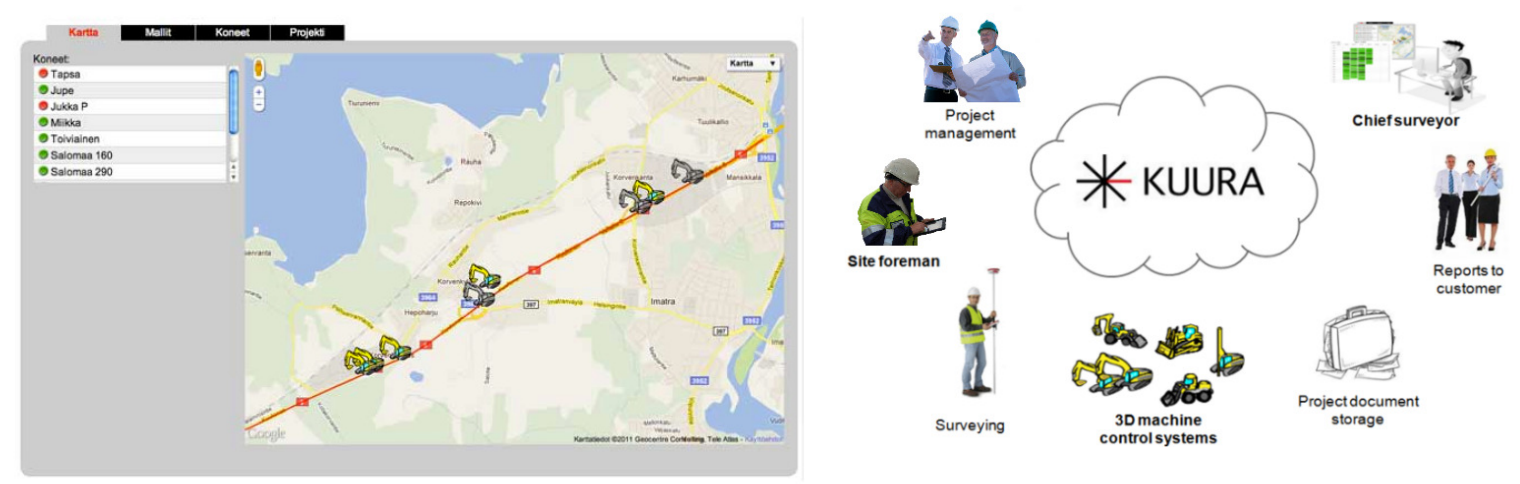

Figure 6. An example of commercial systems for dynamic management of road construction sites - Kuura system (Hohtolabs Oy, Finland).

\section{CONCLUSIONS}

An expectation for the next generation for more dynamic road construction management methods is concluded. The most important functional areas of the dynamic road construction management are the tracking and control of scheduling, costs, materials, the workmen of main contractor, work machines, workmen and other resources of sub-contractors and traffic inside the construction project area. The management of the road construction with present traditional ways is also quite dynamic. The transition to the new type of dynamic management method and systems is, however, a very large change for road contractor and the whole infra industry as well. Today contractors used different systems and software for the tracking and control of the main functions, which remain to have quite inadequate features and possibilities for dynamic information transfer. There are some new systems and software recently come into market, which can be evaluated to be quite dynamic systems and methods. Also significant benefits have been observed and at least orally reported by the contractors in question. The functions and the properties of these commercial systems are still quite limited and inadequate when considering the large integrated utilization of the dynamic management principles. The prototype created in the Finnish DigiINFRA research project is one example and model to the product development work needed for that kind of extended dynamic management system. In this future work, the roles of open information transfer and system integration will be probably significant.

\section{REFERENCES}

Aðalsteinsson, D. H. (2008) GPS machine guidance in construction equipment. Reykjavik, Reykjavik University. 69 p.

Caterpillar (2006) Road Construction Production Study. Caterpillar, Malaga Demonstration \& Learning Center, Spain. 26 p.

Heikkilä, R. \& Jaakkola, M. (2006) Automation of Road Construction - the State of the Art in Europe. ISARC'2006, The 23rd International Symposium on Automation and Robotics in Construction, 35 October 2006, Tokyo, Japan, pp. 7-10.

Kilpeläinen, P. \& Heikkilä, R. \& Parkkila, T. (2007) Automation and Wireless Communication Technologies in Road Rehabilitation. ISARC'2007, The 24th International Symposium on Automation and Robotics in Construction, 19-21 September 2007, Kochi, Kerala, India, pp. 35-40. 
Ligier, A. \& Fliedner, J. \& Kajanen, J. \& Peyret, J. (2001) Open System for Road Information Support. ISARC'2001, The 18th International Symposium on Automation and Robotics in Construction, September 10-12, 2001, Krakow, Poland.

Peyret, F. \& Jurasz, J. \& Carrel, A. \& Zekr, E. \& Gorham, B. (2000) The Computer Integrated Road Construction project. Automation in Construction 9, pp. 447-461.

Viljamaa, E. \& Kilpeläinen, P. \& Pentikäinen, V. \& Sarjanoja, E.-M. \& Heikkilä, R. (2009) On-line Process Management of Pavement Laying Using Wireless Communication Technologies. ISARC'2009, The 26th International Symposium on Automation and Robotics in Construction, 24-27 June 2009, Austin, Texas, U.S.A., pp. 348-356.

Viljamaa, E. \& Peltomaa, I. \& Heikkilä, R. \& Hovila, J. (2012) Advanced Process Control for Infrastructure Building Processes. The 29th International Symposium on Automation and Robotics in Construction, 26 June - 29 June, 2012, Eindhoven, the Netherlands, Abstract p. 67, Full Paper doi:10.4017/gt.2012.11.02.229.632

Viljamaa E. \& et al, Applying web and information integration technologies for intensified construction process control, ISARC 30th International Symposium on Automation and Robotics in Construction in Mining, 2013.

West, T.H. \& Velinsky, S.A. \& Ravani, B. (1995) Advanced Highway Maintenance and Construction Technology Applications: The Future Generation of Highway Machinery. TR News, No. 176, pp. 17-23.

Woo, Dah-Cheng (1995) Robotics in Highway Construction \& Maintenance. Public Roads On-Line, Winter, Vol. 58, No. 3, 6 p. 